\title{
ANALISIS VALUASI SAHAM BUMN MENGGUNAKAN METODE DIVIDEND DISCOUNTED MODEL DAN ECONOMIC VALUE ADDED
}

\author{
Irvan Liunardi Senjaya \\ Institut Teknologi Bandung, Bandung \\ irvanv79@gmail.com
}

\begin{abstract}
ABSTRAK
Penelitian ini ditujukan untuk analisis valuasi saham BUMN dengan model dividend discounted model dan economic value added. Penelitian ini juga hendak mengajarkan investor pemula mengenai analisis laporan keuangan, yang berisi informasi mengenai keuangan perusahaan dan aksi perusahaan di tahun-tahun berikutnya. Analisis laporan keuangan tidak hanya menggunakan pendekatan Price to Earnings Ratio (P/E Ratio) dan Price to Book Value (PBV). Masih banyak analisis yang dapat digunakan, seperti dividend discounted model yang bertujuan untuk mencari nilai intrinsik perusahaan dan economic value added yang bertujuan untuk mencari nilai ekonomi yang akan menguntukan bagi investor. Untuk penelitian ini, peneliti membutuhkan 12 BUMN untuk digunakan sebagai sampel dan data sekunder. Data yang digunakan untuk penelitian yaitu laporan keuangan (periode 2015-2019) dan dividen per lembar saham (periode 2015-2019). Data yang digunakan merupakan data sebelum adanya CoVID-19. Hasil menunjukkan dari dividend discounted model dan economic value added bahwa 7 dari 12 BUMN adalah undervalued dan memiliki nilai ekonomi untuk investor.

Kata Kunci: Pasar Modal, Badan Usaha Milik Negara, Dividend Discounted Model, Economic Value Added, Analisis Deskriptif
\end{abstract}

\section{ABSTRACT}

This research is aimed at analyzing the valuation of BUMN shares with the dividend discounted model and economic value added model. This study is also aimed to teach early or novice investors about financial statement analysis, which contains information about companies' finances and companies' actions in the following years. Financial statement analysis is not limited to the Price-to-Earnings Ratio (P/E Ratio) and Price-to-Book Value (PBV). There are various analyses that can be used, such as the dividend discounted model aiming to find the company's intrinsic value and economic value added aiming to find economic value that will benefit investors. For this research, the researchers need 12 state-owned-enterprises (SOEs) to be used as samples and secondary data. The data used for this research are financial statements (2015-2019 period) and dividends per share (2015-2019 period). The data used were obtained before the event of CoVID-19. The results show that from the dividend discounted model and economic value added, 7 out of 12 SOEs are undervalued and have economic value for investors.

Keywords: Capital Markets, State-Owned-Enterprises, Dividend Discounted Model, Economic Value Added, Descriptive Analysis

\section{PENDAHULUAN}

Pasar modal merupakan tempat bagi investor untuk menanamkan modal dengan berbagai macam instrumen yang bebas dipilih oleh investor. Instrumen tersebut antara lain saham, obligasi, reksadana, deposito, dan sebagainya. Di dalam pasar modal, terdapat investor yang memiliki dana untuk diinvestasikan pada perusahaan yang akan memberikan keuntungan dan investee yang membutuhkan dana untuk keberlangsungan usaha. Maka dari itu, Bursa Efek Indonesia sebagai penengah dari kedua belah pihak untuk menawarkan saham investee kepada investor di Pasar Modal Indonesia.

Seiring berjalannya waktu, masyarakat yang mengetahui pasar modal sudah mencapai angka $80 \%$, namun untuk literasinya masih di angka 37\% di tahun 2019 (Sidik, 2020). Walaupun pada tahun 2020 naik menjadi 38\% (Wicaksono, 2020) namun tetap belum seimbang dengan peningkatan orang yang masuk ke pasar modal. Investor saham mengalami kesulitan untuk mencari perusahaan yang bagus di Indonesia dikarenakan keterbatasan pengetahuan dalam memvaluasi suatu perusahaan. Valuasi yang biasa digunakan oleh investor antara lain Price to Earnings Ratio (PER) dan Price to Book Value (PBV) hanya untuk memvaluasi perusahaan berdasarkan pendapatan per saham dan nilai buku perusahaan berbanding dengan nilai saham saat ini. Sudut pandang baru mengenai valuasi dibutuhkan agar investor memiliki wawasan mengenai valuasi perusahaan di setiap industri, 
tidak hanya satu jenis metode valuasi namun berbagai metode telah ada dengan pendekatan untuk industri yang berbeda, seperti Price to Book Value (PBV) yang lebih cocok untuk perbankan ataupun Price to Earnings Ratio (PER).

BUMN merupakan Badan Usaha Milik Negara yang dimiliki oleh Negara Kesatuan Republik Indonesia (NKRI) untuk mendapatkan keuntungan dari hasil penjualan dan digunakan untuk kepentingan negara serta BUMN tersebut. Pemilihan BUMN yang sudah listing di IDX untuk penelitian ini dikarenakan BUMN merupakan perusahaan yang mayoritas sahamnya dimiliki negara, yaitu Indonesia. Sehingga laporan keuangan BUMN dapat menjadi data yang menarik untuk di valuasi agar mengetahui undervalued/overvalued saham BUMN. Selain itu, data BUMN yang telah listing lebih mudah didapatkan karena telah disebar ke masyarakat luas untuk data kuartal ataupun data tahunan.

Maka dari itu, penelitian yang dilakukan ini akan membahas mengenai metode valuasi serta penggunaan untuk menilai perusahaan yang murah (undervalued) atau mahal (overvalued) berdasarkan dua metode valuasi yaitu dividend discounted model dan economic value added. Valuasi menggunakan dua metode tersebut dikarenakan investor membutuhkan sudut pandang terkait valuasi menggunakan dividen yang diberikan BUMN setiap periode serta tambahan nilai ekonomis yang dihasilkan selama BUMN Persero beroperasi setiap periode. Sumber data menggunakan data keuangan selama lima tahun (2015-2019) agar hasil yang diperoleh nantinya akan lebih valid dibandingkan penggunaan periode yang lebih pendek.

\section{KAJIAN TEORI}

Kajian teori merupakan pengumpulan ide, konsep, dan perkembangan topik yang berasal dari sumber ilmiah seperti buku, artikel jurnal ataupun tesis. Kajian teori harus berkaitan dengan rumusan masalah, pertanyaan penelitian, maupun tujuan penelitian. Tandelilin $(2017$, p. 3$)$ mengungkapkan bahwa investasi merupakan aktivitas yang menaruh dana pada suatu instrumen investasi untuk memaksimalkan penggunaan kas yang dimiliki agar mendapatkan keuntungan di masa yang akan datang. Menurut Salim (2010, pp. 1-2), investor dapat menaruh uangnya di instrumen investasi yang diinginkan, dengan tujuan mendapatkan return yang sesuai dengan risikonya. Selain itu Subramanyam \& Wild (2017) menjelaskan bahwa investasi memiliki rentang waktu yang relatif baik pendek ataupun panjang, dengan harapan imbal hasil yang berbeda sesuai dengan risiko yang diambil serta hasil yang diharapkan positif untuk investasinya.

Menurut Herlianto (2013), Terdapat 5 proses yang akan digunakan untuk mengatur investasi, antara lain.

1. Perencanaan Portofolio

Tujuan dari perencanaan portofolio yaitu untuk menentukan jangka waktu atas tujuan investasi serta mengatur risiko dan potensi imbal hasil yang akan diterima investor.

2. Analisis Portofolio

Mengumpulkan data bersifat kualitatif dan kuantitatif untuk investasi yang akan dijadikan bagian dari portofolio investor tersebut.

3. Membentuk Portofolio

Membentuk investasi portofolio dengan melakukan seleksi terhadap berbagai jenis investasi yang ada dan menyesuaikan waktu investasi yang telah dipilih.

4. Evaluasi Portofolio

Melakukan pengukuran dan perbandingan pada setiap jenis investasi dalam portofolio investasi sesuai dengan patokan.

5. Revisi Portofolio

Revisi portofolio dilakukan jika hasil investasi yang diterapkan tidak sesuai dengan tujuan investasi.

Tandelilin (2017, p. 26) mengungkapkan bahwa pasar modal merupakan tempat bertemunya investor dengan perusahaan yang membutuhkan dana untuk mengembangkan perusahaannya dengan menerbitkan efek berupa surat hutang ataupun menerbitkan saham. Selain itu Setiawan (2015, p. 38) menjelaskan bahwa pasar modal juga berguna untuk percepatan pembangunan perusahaan melalui dana segar yang didapat agar perencanaan pembangunan bisa sesuai dengan hasil yang diinginkan perusahaan. Aktivitas di pasar modal yang terjadi (Herlianto, 2013, pp. 910), serta sistem pasar modal yang terorganisir

https://doi.org/10.26593/jab.v17i2.5022.115-128 
dengan baik dapat digunakan sebagai indikator untuk menilai percepatan pembangunan sebuah negara.

Herlianto (2013) menjelaskan bentuk investasi dibagi menjadi dua, yaitu sektor riil dan sektor finansial. Sektor riil antara lain properti dan emas. Untuk sektor finansial, instrumen investasi berupa saham, reksadana, obligasi, dan instrumen turunannya (derivatif).

Menurut Hartono (2017, pp. 7-29), instrumen pasar modal yaitu instrumen investasi langsung, yang dikelola langsung oleh investor seperti deposito, obligasi, saham, derivatif. Selain itu, instrumen investasi langsung yang dikelola oleh manajer investasi, antara lain reksadana.

Sedangkan menurut Tandelilin (2017, pp. 30-31), instrumen pasar modal atau disebut sekuritas merupakan aset finansial yang menyatakan klaim keuangan dan diperdagangkan di pasar finansial/financial markets yang terdiri dari pasar modal dan pasar uang. Sekuritas memiliki jangka waktu tempo lebih dari satu tahun dengan harapan agar membedakan antara pasar uang dengan pasar modal.

Berdasarkan paparan di atas, instrumen pasar modal merupakan aset finansial dari investor yang dapat dibagi menjadi instrumen sektor riil dan sektor finansial. Sektor riil merupakan tanah, rumah, apartemen. Sedangkan sektor finansial dibagi menjadi pasar modal (obligasi, saham, derivatif) dan pasar uang (deposito, Sertifikat Bank Indonesia). Investor dapat mengelola secara langsung ataupun tidak langsung, yaitu dikelola oleh manajer investasi, seperti reksadana.

Subramanyam \& Wild

menjelaskan bahwa saham merupakan sebuah kepemilikan perusahaan dalam bentuk sertifikat dengan risiko dan imbal hasil yang tinggi. Imbal hasil yang didapat melalui investasi saham dapat berupa capital gain dan dividen (Herlianto, 2013). Terdapat beberapa jenis saham, diantaranya saham biasa dan saham preferen. Menurut Tandelilin (2017), kepemilikan saham biasa memiliki hak suara proporsional pada berbagai keputusan penting perusahaan di Rapat Umum Pemegang Saham. Namun, untuk saham preferen, pemegang saham preferen tidak memiliki hak dalam RUPS, namun mendapatkan dividen yang lebih tinggi.
Berdasarkan teori yang ada di atas, dapat disimpulkan bahwa setiap saham memiliki karakterisik yang berbeda, contoh seperti saham biasa/common stocks yang memiliki hak untuk mengikuti Rapat Umum Pemegang Saham (RUPS) dan Rapat Umum Pemegang Saham Luar Biasa (RUPSLB), namun saham biasa mendapatkan hak terakhir atas likuidasi perusahaan, setelah membagikannya kepada karyawan, kreditur, dan pemegang saham preferen, menurut UndangUndang Pasar Modal (1995).

Sedangkan saham preferen memiliki hak untuk mendapatkan dividen langsung dari laba bersih dikurangi dengan jumlah pemegang saham preferen. Hitungan dividen saham preferen berdasarkan nilai nominal yang ditetapkan oleh perusahaan, apakah menggunakan metode parvalue atau no-par value. Pemegang saham preferen juga memiliki hak untuk mendapatkan dividen dan aset dari perusahaan jika terjadi likuidasi setelah pajak, karyawan, dan kreditur. Namun, pemegang saham preferen tidak memiliki hak untuk mengikuti Rapat Umum Pemegang Saham (RUPS) dan Rapat Umum Pemegang Saham Luar Biasa (RUPSLB) dikarenakan pemegang saham preferen hanya berhak untuk dividen saja, namun tidak untuk melakukan voting atas perusahaan (Hartono J. , 2017, pp. 190-191).

Saham berbeda dengan obligasi, dimana saham akan mendapatkan dividen setiap satu hingga dua kali setahun yang besarannya telah ditentukan di Rapat Umum Pemegang Saham Tahunan (RUPST) beserta dengan para pemegang saham. Para pemegang saham biasa dapat menerima pembagian keuntungan serta voting untuk memimpin perusahaannya selama beberapa tahun ke depan, dan memiliki hak preemptif (preemptive right) yang berfungsi agar investor mendapatkan kesempatan berupa persentasi kepemilikan yang sama jika perusahaan mengeluarkan tambahan lembar saham di pasar. Saham memiliki karakteristik yang berbeda dengan obligasi, bahwa saham merupakan sebuah kepemilikan perusahaan, sedangkan obligasi merupakan bentuk pinjaman perusahaan kepada investor dikarenakan perusahaan membutuhkan uang tersebut untuk aktivitas perusahaan (Hartono J. , 2017). 
Karakteristik saham preferen dan saham biasa berbeda satu sama lain. Dimana saham preferen berhak mendapatkan dividen yang lebih besar dibandingkan saham biasa, sedangkan saham biasa berhak untuk mendapatkan dividen dan voting untuk menentukan jalannya perusahaan selama beberapa tahun ke depan. Saham merupakan sebuah kepemilikan, sedangkan obligasi merupakan sebuah surat hutang kepada investor karena membutuhkan uang untuk aktivitas perusahaan. Para pemegang saham biasa berhak datang ke RUPS dan RUPSLB, sedangkan pemegang saham preferen dan pemegang obligasi tidak berhak dikarenakan bukan pemilik dan pemegang saham biasa perusahaan.

Badan Usaha Milik Negara (BUMN) merupakan badan usaha yang seluruh atau sebagian besar modalnya dimiliki oleh negara melalui penyertaan secara langsung yang berasal dari kekayaan negara yang dipisahkan (Undang Undang Badan Usaha Milik Negara, 2003). BUMN bertujuan untuk menyediakan kebutuhan vital bagi masyarakat dengan harga yang dapat dijangkau oleh masyarakat, sehingga BUMN dapat membangun ekonomi menjadi lebih besar untuk menciptakan kemakmuran. Dana BUMN bersumber dari Anggaran Pendapatan dan Belanja Negara ataupun dari pasar modal dengan penerbitan saham dan obligasi (Arta, 2017, pp. 178-179). Ginting (2017) menjelaskan, dengan penerbitan saham dan obligasi ke publik, maka BUMN mendapatkan kepercayaan dari stakeholders. Sehingga stakeholders dapat meminjamkan dana kepada BUMN dikarenakan citra BUMN yang baik dan kinerja yang memuaskan sepanjang waktu.

Fauziah (2014, pp. 85-104) menyatakan bahwa resiko merupakan ukuran ketidakpastian yang mengelilingi imbal hasil yang akan didapat dari investasi. Subramanyam \& Wild (2017) menjelaskan bahwa risiko muncul dikarenakan keuntungan perusahaan yang fluktuatif dan hutang perusahaan yang besar, menyebabkan perusahaan harus dikelola dengan baik agar risiko bisa diminimalisir dengan baik. Sementara return menurut Gitman \& Zutter (2015) merupakan imbal hasil yang diharapkan oleh seorang investor di masa yang akan datang.
Zahera \& Bansal (2018) menjelaskan bahwa persepsi merupakan kemampuan seorang investor untuk memiliki berbagai sudut pandang mengenai pasar modal. sehingga menurut Khan, Tan, dan Chong (2017), seorang investor dapat mengetahui sisi optimis dan pesimis dari pengambilan keputusan untuk membeli sebuah aset di pasar modal. Sudut pandang tersebut dapat dilihat dari historis portofolio dan risiko yang akan terjadi jika mengambil aset berisiko (Olsen, 2014).

Capital Asset Pricing Model (CAPM) merupakan hubungan antara return dan risiko yang tidak bisa dipecah dari perusahaan yang dihitung menggunakan koefisien beta (Gitman \& Zutter, 2015). Hartono J (2017, p. 575) mengungkapkan bahwa CAPM digunakan untuk mengestimasi return saham tertentu dengan menggunakan metode Markowitz untuk pengambilan keputusan investasi. Selain itu, penggunaan beta pada CAPM berfungsi sebagai kovarian return saham ke periode tertentu (Tandelilin, Portofolio dan Investasi, 2017).

Volatilitas merupakan pergerakan harga yang tidak normal pada saham (Gitman \& Zutter, 2015). Purbawati \& Dana (2016, p. 1014) menjelaskan bahwa volatilitas biasanya dapat diramalkan/forecasted dengan melihat pergerakan saham pada kurun waktu tertentu dilihat dari penawaran dan permintaan saham di pasar modal. Pergerakan saham juga akan bergerak relatif terhadap ekspektasi imbal hasil saham, sehingga pergerakan saham cenderung tidak akan bergerak terlalu liar jika tidak ada pengendali saham tersebut (Raneo \& Muthia, 2018). Hartono (2017) menjelaskan bahwa beta merupakan suatu pengukur sensitivitas return sekuritas atau return portofolio terhadap return pasar. Beta yang menilai satu (1) memiliki arti bahwa risiko portofolio sama dengan risiko pasar. Beta tersebut menunjukkan bahwa terdapat perubahan return pasar dan portofolio sebesar $\mathrm{x} \%$ yang akan berubah sesuai dengan waktu (Echterling \& Eierle, 2015, p. 780). Beta merupakan ukuran risiko relatif yang mencerminkan risiko relatif saham individual terhadap portofolio pasar saham secara keseluruhan.

Menurut Subramanyam \& Wild (2017), analisis kinerja emiten didasarkan pada dua 
analisis, yaitu analisis fundamental dan analisis teknikal. Analisis fundamental merupakan proses untuk menentukan valuasi perusahaan berdasarkan laporan keuangan yang diterbitkan dan performa kinerja perusahaan selama beberapa tahun ke belakang. Analisis menurut Tandelilin (2017) didasarkan pada tiga hal, yaitu analisis variabel ekonomi dan pasar modal, analisis industri, dan analisis perusahaan. Analisis fundamental merupakan salah satu metode yang menggunakan berbagai macam rasio untuk menganalisis perusahaan, dinilai dari likuiditas, aktivitas, solvabilitas, profitabilitas, dan harga pasar (Isidore \& Christie, 2018). Analisis teknikal menurut Ong (2016) merupakan sebuah keilmuan untuk mempelajari tentang pergerakan arah harga dan trend yang telah dibentuk oleh investor berdasarkan data harga dan volume historis untuk memprediksi pergerakan arah harga dan trend di masa yang akan datang.

Metode dividend discounted model (DDM) merupakan metode yang efektif digunakan pada emiten yang rajin membagikan dividen, berfungsi untuk memprediksi dividen yang akan diberikan di masa depan (Wright \& Sim, 2018). Metode tersebut menurut Olweny (2011, pp. 127128) memprediksi valuasi perusahaan berdasarkan dividen yang diberikan. Sehingga menurut Ivanovski, Ivanovska \& Narasanov (2015, pp. 148-149) metode DDM dapat mempresentasikan notasi normal dari pernyataan bahwa harga saham bergantung terhadap imbal hasil yang diharapkan.

Metode economic value added (EVA) menurut Sharma (2010) merupakan indikator untuk mengukur efisiensi manajemen dalam mengelola perusahaan untuk mendapatkan keuntungan ekonomi dalam menjalankan perusahaan. Selain itu, menurut Costin (2017, pp. 168-169) dapat digunakan untuk mengukur performa perusahaan dengan bergantung pada nilai tambah pada produk yang dijual oleh perusahaan. EVA perusahaan hanyalah sebuah pengukuran dari selisih pendapatan investasi yang dihasilkan melalui imbal hasil rata-rata pasar (Sabrol \& Sverer, 2016, pp. 20-21).

Menurut Damodaran (1995), valuasi dapat digunakan untuk berbagai macam aktivitas yang berhubungan dengan keuangan, seperti pasar modal, corporate finance, dan analisa akusisi (acquisition analysis). Untuk pasar modal, valuasi digunakan oleh investor yang memiliki orientasi jangka panjang dengan fokus pada nilai perusahaan di saat ini dan masa mendatang. Untuk investor yang berorientasi jangka pendek, valuasi lebih jarang digunakan sebagai tolak ukur investasi dan market timing akan lebih diandalkan kedepannya.

Menurut Gitman \& Zutter (2015), berikut merupakan perhitungan metode dividend discounted model

Value of the stock $=$ Expected dividends next period/(Cost of equity expected growth rate in perpetuity)

Metode DDM yang dipakai yaitu metode Gordon Model. Tahapan yang dibutuhkan yaitu expected dividends next period, atau dengan persamaan sebagai berikut:

$$
P_{0}=\frac{D_{0} x(1+g)^{1}}{\left(1+r_{s}\right)^{1}}+\frac{D_{0} x(1+g)^{2}}{\left(1+r_{s}\right)^{2}}+\cdots
$$

Atau, disederhanakan menjadi seperti ini

$$
P_{0}=\frac{D_{1}}{\left(r_{s}-g\right)}
$$

Komponen yang dibutuhkan untuk membuat analisis berdasarkan dividend discounted model yaitu:

$$
D_{1}=D_{0} x(1+g)^{n}
$$

$$
R_{S}=R O E x(1-D P R)
$$

$$
g=\frac{D_{n}-D_{0}}{D_{0}}
$$

Sedangkan untuk metode EVA, tahapan perhitungan economic value added menurut Damodaran (1995), yaitu:

$E V A=($ Return on Capital Invested -

Cost of capital) $x$ (Capital invested)

EVA memperhitungkan jumlah uang yang dihasilkan ditambahkan value produk yang dibuat oleh perusahaan di investasi yang sudah ada. 


\section{METODOLOGI}

Metode penelitian merupakan cara ilmiah untuk mengumpulkan, mengolah, dan menganalisis data agar data tersebut dapat diinterpretasikan melalui hasil angka yang lebih tersusun rapi atau melalui kalimat. Hasil yang diperoleh melalui penelitian berupa data empiris yang memiliki kriteria valid (Sugiyono P. , 2018, p. 2). Terdapat dua metode penelitian, yaitu metode kualitatif dan kuantitatif. Penelitian ini, menggunakan metode kuantitatif dikarenakan data yang disajikan berupa angka, sehingga perlu diinterpretasikan dalam bentuk angka dan kalimat berupa hasil analisis dari data tersebut yang berupa angka.

Tipe penelitian yang akan digunakan untuk penelitian ini yaitu analisis deskriptif dengan menggunakan metode penelitian kuantitatif. Mulyadi mengungkapkan bahwa metode kuantitatif merupakan kemampuan untuk melakukan generalisasi atas hasil penelitian berdasarkan pengumpulan data (2011, pp. 132133). Untuk sumber data yang digunakan dalam penelitian kuantitatif adalah data kuantitatif yaitu adjusted beta dari PEFINDO dan metode valuasi (Dividend Discounted Model dan Economic Value Added) dari BUMN Persero Tbk. yang akan dijadikan sampel penelitian.

Teknik pengumpulan data, menurut Sugiyono (2018, p. 137) dilakukan dengan berbagai sumber dan cara. Terdapat dua sumber, yaitu sumber primer dan sumber sekunder. Sumber primer didapat dari data langsung seperti dari wawancara yang kemudian diolah. Sedangkan sumber sekunder merupakan data tidak langsung atau berupa data dari laman web, laporan keuangan, buku, jurnal, dan sebagainya. Untuk data penelitian ini, digunakan data sekunder yang terdiri dari:

a. Laporan keuangan perusahaan BUMN (Persero), Tbk. Periode 2015 hingga 2019

b. Beta Pefindo

c. Buku dan jurnal yang memuat teori tertentu

d. Metode valuasi (DDM \& EVA)

Populasi merupakan wilayah generalisasi yang terdiri atas obyek/subyek yang memiliki kualitas dan karakteristik tertentu untuk dipelajari dan ditarik kesimpulan. Sedangkan sampel merupakan bagian dari jumlah dan karakteristik dari populasi tersebut (Sugiyono P. , 2018, pp. 8081). Untuk populasi yang digunakan yaitu seluruh saham perusahaan BUMN (Persero), Tbk. Periode 2015 hingga 2019. Untuk sampel, terdapat beberapa kriteria yang digunakan, yaitu:

Tabel 1. Kriteria Sample Penelitian

\begin{tabular}{|l|l|l|}
\hline No & Kriteria pumlah & Jum \\
\hline 1 & $\begin{array}{l}\text { Memiliki status perusahaan BUMN } \\
\text { (Persero), Tbk. }\end{array}$ & 19 \\
\hline 2 & $\begin{array}{l}\text { Memiliki kapitalisasi pasar diatas Satu (1) } \\
\text { Triliun Rupiah }\end{array}$ & 19 \\
\hline 3 & $\begin{array}{l}\text { Tidak pernah mengalami suspensi } \\
\text { perdagangan periode 2015-2019 }\end{array}$ & 16 \\
\hline 4 & Masuk ke dalam indeks LQ45 & 13 \\
\hline 5 & Perusahaan sering membagikan dividen & 12 \\
\hline
\end{tabular}

Untuk penelitian ini, hasil yang akan digunakan oleh penulis yaitu sebanyak 12 sampel dengan kriteria "Masuk ke dalam indeks LQ45". Tabel 2. Perusahaan BUMN yang menjadi Sample dalam Penelitian ini.

\begin{tabular}{|c|c|c|c|}
\hline No & $\begin{array}{l}\text { Kode } \\
\text { Emiten }\end{array}$ & Nama Perusahaan & Sub Industri \\
\hline 1 & ANTM & $\begin{array}{l}\text { PT. Aneka } \quad \text { Tambang } \\
\text { (Persero), Tbk. }\end{array}$ & $\begin{array}{l}\text { Pertambangan } \\
\text { (Emas) }\end{array}$ \\
\hline 2 & BBNI & $\begin{array}{l}\text { PT. Bank Negara Indonesia } \\
\text { (Persero), Tbk. }\end{array}$ & Perbankan \\
\hline 3 & BBRI & $\begin{array}{l}\text { PT. Bank Rakyat Indonesia } \\
\text { (Persero), Tbk. }\end{array}$ & Perbankan \\
\hline 4 & BBTN & $\begin{array}{l}\text { PT. Bank Tabungan Negara } \\
\text { (Persero), Tbk. }\end{array}$ & Perbankan \\
\hline 5 & BMRI & $\begin{array}{l}\text { PT. Bank Mandiri (Persero), } \\
\text { Tbk. }\end{array}$ & Perbankan \\
\hline 6 & JSMR & $\begin{array}{l}\text { PT. Jasa Marga (Persero), } \\
\text { Tbk. }\end{array}$ & $\begin{array}{l}\text { Penyedia } \\
\text { Layanan Jalan } \\
\text { Tol }\end{array}$ \\
\hline 7 & PGAS & $\begin{array}{l}\text { PT. Perusahaan Gas Negara } \\
\text { (Persero), Tbk. }\end{array}$ & Energi (Gas) \\
\hline 8 & PTBA & $\begin{array}{l}\text { PT. Bukit Asam (Persero), } \\
\text { Tbk. }\end{array}$ & $\begin{array}{l}\text { Pertambangan } \\
\text { (Batu Bara) }\end{array}$ \\
\hline 9 & PTPP & $\begin{array}{l}\text { PT. Pembangunan Perumahan } \\
\text { (Persero), Tbk. }\end{array}$ & Konstruksi \\
\hline 10 & SMGR & $\begin{array}{l}\text { PT. Semen Indonesia } \\
\text { (Persero), Tbk. }\end{array}$ & Semen \\
\hline 11 & TLKM & $\begin{array}{l}\text { PT. Telekomunikasi } \\
\text { Indonesia (Persero), Tbk. }\end{array}$ & $\begin{array}{l}\text { Telekomunika } \\
\text { si }\end{array}$ \\
\hline 12 & WIKA & $\begin{array}{l}\text { PT. Wijaya Karya (Persero), } \\
\text { Tbk }\end{array}$ & Konstruksi \\
\hline
\end{tabular}




\section{Operasionalisasi Variabel}

Terdapat beberapa langkah perhitungan metode Dividend Discounted Model dan Economic Value Added (DDM \& EVA) berdasarkan laporan keuangan masing-masing untuk menilai kinerja perusahaan BUMN.

Tahapan Perhitungan Metode Dividend Discounted Model

a. Dividend Growth Rate

$$
g=\frac{D_{n}-D_{0}}{D_{0}}
$$

Keterangan:

$\mathrm{g}=$ tingkat pertumbuhan dividen

$D_{n}=$ dividen saat ini

$D_{0}=$ dividen tahun sebelumnya

b. Estimasi Dividen

$$
D_{1}=D_{0}(1+\dot{\mathrm{g}})
$$

Keterangan:

$D_{\mathrm{t}}=$ Estimasi Dividen

$\mathrm{D}_{0}=$ Dividen tahun sebelumnya

$\dot{\mathrm{g}}=$ Rata-rata pertumbuhan dividen

\section{c. Required Rate of Return}

$$
R_{S}=R O E \times(1-D P R)
$$

\section{Keterangan}

$\mathrm{Rs}=$ Required Rate of Return (Saham)

$\mathrm{ROE}=$ Return on Equity

$\mathrm{DPR}=$ Dividend Payout Ratio

d. Penilaian intrinsik saham dengan metode constant growth model

$$
P_{0}=\frac{D_{1}}{R_{s}-\dot{\mathrm{g}}}
$$

Keterangan:

$\dot{\mathrm{g}}=$ tingkat pertumbuhan dividen

Dn $=$ Dividen saat ini

D0 $=$ Dividen tahun sebelumnya

1. Tahapan Perhitungan Metode Economic Value Added

$$
\mathrm{EVA}=\mathrm{NOPAT}-(\mathrm{WACC} \times \mathrm{IC})
$$

Keterangan

$\mathrm{EVA}=$ Economic Value Added

NOPAT $=$ Net Operating Profit After Tax

WACC $=$ Weighted Average Cost of Capital

$$
\mathrm{IC}=\text { Invested Capital }
$$

$$
\text { NOPAT }=\text { EBIT } x(1-T)
$$

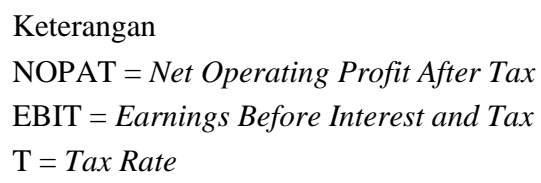

2. WACC

$$
\frac{\text { Debt }}{\text { Debt+Equity }} R d(1-T)+\frac{\text { Equity }}{\text { Debt }+ \text { Equity }} R e
$$

$$
\begin{aligned}
& \text { Keterangan } \\
& \text { WACC }=\text { Weighted Average Cost of Capital } \\
& \text { Debt }=\text { Hutang berbunga } \\
& \text { Equity = Modal } \\
& \mathrm{Rd}=\text { Required return of Debt } \\
& \mathrm{T}=\text { Tax Rate } \\
& \mathrm{Re}=\text { Required return of Equity }
\end{aligned}
$$

3. Invested Capital $=($ Total Debt + Total Equity $)$ - Short Term Liabilities

$$
\begin{aligned}
& \text { Invested Capital }=(\text { Total Debt }+ \\
& \text { Total Equity })- \text { Short Term Liabilities }
\end{aligned}
$$

Keterangan

Invested Capital $=$ Biaya modal yang diinvestasikan oleh perusahaan

Total Debt $=$ Total hutang berbunga perusahaan

Total Equity = Total modal yang dimiliki perusahaan

Short Term Liabilities $=$ Liabilitas jangka pendek

Tabel 3. Kriteria Penilaian Nilai Intrinsik metode DDM

\begin{tabular}{|l|l|}
\hline \multicolumn{2}{|l|}{ Kriteria Penilaian Nilai Intrinsik } \\
\hline P0 > Closing Price & $\begin{array}{l}\text { Saham tersebut undervalued. } \\
\text { Investor disarankan membeli } \\
\text { saham tersebut. }\end{array}$ \\
\hline P0 = Closing Price & $\begin{array}{l}\text { Saham berada di posisi yang } \\
\text { sama antara nilai intrinsik } \\
\text { dengan nilai pasar saham. }\end{array}$ \\
\hline P0 < Closing Price & $\begin{array}{l}\text { Saham tersebut } \text { overvalued. } \\
\text { Investor disarankan menjual } \\
\text { saham tersebut. }\end{array}$ \\
\hline
\end{tabular}

Metode analisis deskriptif bertujuan untuk mengolah sampel dengan membuat analisis berdasarkan pertanyaan $5 \mathrm{~W}+1 \mathrm{H}$ dan bentuk generalisasi, sehingga setiap orang mengerti analisis yang dibuat di dalam penelitian ini. 


\section{PEMBAHASAN DAN HASIL PENELITIAN}

Pembahasan pada penelitian ini menggunakan metode dividend discounted model dan economic value added. Sehingga mendapatkan perhitungan sebagai berikut.

\section{Metode Dividend Discounted Model}

Tabel 4. Hasil Perhitungan Metode Dividend Discounted Model

\begin{tabular}{|c|c|c|c|c|c|}
\hline $\begin{array}{l}\text { Kode } \\
\text { Emiten }\end{array}$ & D0 & D1 & CAPM & G & P0 \\
\hline ANTM & $\operatorname{Rp} 2,82$ & $\operatorname{Rp} 2,83$ & 0,1148 & 0,007 & $\operatorname{Rp} 26,24$ \\
\hline $\mathrm{BBNI}$ & Rp 206,24 & $\operatorname{Rp} 225,23$ & 0,1064 & 0,094 & $\operatorname{Rp} 18.341,57$ \\
\hline BBRI & Rp 168,20 & Rp 185,43 & 0,3517 & 0,066 & Rp 4963,35 \\
\hline BBTN & $\operatorname{Rp} 1,97$ & $\mathrm{Rp} 2,14$ & 0,1056 & 0,007 & Rp 21,69 \\
\hline BMRI & $\operatorname{Rp} 353,34$ & Rp 376,43 & 0,0997 & 0,074 & $\operatorname{Rp} 14.520,91$ \\
\hline JSMR & $\mathrm{Rp} 15,2$ & Rp 16,35 & 0,1003 & 0,073 & $\operatorname{Rp} 588,77$ \\
\hline PGAS & Rp 41,56 & Rp 43,86 & 0,1152 & 0,065 & Rp 875,84 \\
\hline PTBA & Rp 326,46 & $\operatorname{Rp} 364,76$ & 0,1126 & 0,04 & Rp 5.027,07 \\
\hline PTPP & Rp 33,84 & Rp 36,93 & 0,1268 & 0,055 & $\operatorname{Rp} 516,51$ \\
\hline SMGR & $\operatorname{Rp} 40,3$ & $\operatorname{Rp} 47,35$ & 0,1099 & 0,067 & Rp 1.104,86 \\
\hline TLKM & $\operatorname{Rp} 154,06$ & Rp 164,87 & 0,0895 & 0,026 & Rp 2.603,98 \\
\hline WIKA & $\operatorname{Rp} 50,95$ & $\operatorname{Rp} 56,86$ & 0,1205 & 0,089 & Rp 1.797,48 \\
\hline
\end{tabular}

Berdasarkan data berikut, langkah menganalisis data sebagai berikut:

Tabel 5. Komponen untuk perhitungan metode DDM

\begin{tabular}{|l|l|}
\hline D0 & Dividen tahun 2019 \\
\hline D1 & Ekspektasi dividen \\
\hline $\mathrm{g}$ & $\begin{array}{l}\text { Ekspektasi pertumbuhan, didapat dari ROE x (1- } \\
\text { DPR) }\end{array}$ \\
\hline CAPM & $\begin{array}{l}\text { Sebagai required rate of return saham, dihitung } \\
\text { menggunakan Adjusted Beta Pefindo, Obligasi 10 } \\
\text { Tahun (Risk Free rate), dan Risk Premium tahun } \\
2019\end{array}$ \\
\hline P0 & $\begin{array}{l}\text { Harga saham berdasarkan perhitungan metode } \\
\text { dividend discounted model }\end{array}$ \\
\hline
\end{tabular}

\section{Metode Dividend Discounted Model}

Berdasarkan metode Dividend Discounted Model, dapat dilihat bahwa terdapat berbagai keputusan atas 13 perusahaan BUMN (Persero) Tbk. untuk membeli atau menjual saham. Untuk saham BBNI< BBRI, BMRI, dan PTBA, direkomendasikan untuk dibeli dikarenakan penilaian valuasi menggunakan metode DDM bahwa keempat saham tersebut masih undervalued. Investor dapat membeli keempat saham tersebut hingga pada akhirnya mencapai overvalued. Sedangkan 8 saham lainnya (ANTM,
BBTN, JSMR, PGAS, PTPP, SMGR, TLKM, dan WIKA) sebaiknya dijual oleh investor, karena menurut metode DDM, 9 saham tersebut dinilai overvalued. Sehingga saham tersebut cenderung sulit untuk naik dan akan muncul potensi untuk mengalami penurunan hingga mencapai nilai intrinsiknya kembali.

Tabel 6. Perhitungan Metode DDM

\begin{tabular}{|c|c|c|c|c|}
\hline & P0 & $\begin{array}{c}\text { Closing } \\
\text { Price }\end{array}$ & $\begin{array}{c}\text { Penilaian } \\
\text { Saham }\end{array}$ & $\begin{array}{c}\text { Keputusa } \\
n\end{array}$ \\
\hline ANTM & Rp 26,24 & Rp 840 & Overvalued & Menjual \\
\hline BBNI & Rp 18.341,57 & $\mathrm{Rp} 7.850$ & Undervalued & Membeli \\
\hline BBRI & Rp 4963,35 & Rp 4.400 & Undervalued & Membeli \\
\hline BBTN & Rp 21,69 & Rp 2.120 & Overvalued & Menjual \\
\hline BMRI & Rp 14.520,91 & Rp 7.675 & Undervalued & Membeli \\
\hline JSMR & Rp 588,77 & Rp 5.175 & Overvalued & Menjual \\
\hline PGAS & Rp 875,84 & Rp 2.170 & Overvalued & Menjual \\
\hline PTBA & Rp 5.027,07 & Rp 2.660 & Undervalued & Membeli \\
\hline PTPP & Rp 516,51 & Rp 1.585 & Overvalued & Menjual \\
\hline SMGR & Rp 1.104,86 & Rp 12.000 & Overvalued & Menjual \\
\hline TLKM & Rp 2.603,98 & Rp 3.970 & Overvalued & Menjual \\
\hline WIKA & Rp $1.797,48$ & Rp 1.990 & Overvalued & Menjual \\
\hline
\end{tabular}

\section{Metode Economic Value Added}

Untuk menghitung Metode Economic Value Added, diperlukan pemotongan angka 000.000.000 untuk penyesuaian data ke dalam tabel. Terdapat beberapa tahap untuk menghitung metode EVA, yaitu:

\section{Menghitung NOPAT}

(Pemotongan 000.000.000 untuk seluruh perhitungan; PGAS menggunakan Dolar Amerika Serikat / US Dolar)

Berdasarkan data Net Operating Profit After Tax (NOPAT), saham ANTM merugi dari tahun 2015 hingga 2017, pada tahun 2018 tidak ada saham BUMN yang rugi, namun saham ANTM kembali merugi pada tahun 2019. Sedangkan untuk saham BBRI dan TLKM memiliki NOPAT yang terbesar dari tahun 2015 hingga tahun 2019. 
Tabel 7. Hasil perhitungan Net Operating Profit After Tax (NOPAT)

\begin{tabular}{|c|c|c|c|c|c|}
\hline & 2015 & 2016 & 2017 & 2018 & 2019 \\
\hline ANTM & $(812.395)$ & $(13.551)$ & $(798.105)$ & 1.197 .413 & $(1.475 .579)$ \\
\hline BBNI & 6.614 .989 & 10.621 .916 & 13.816 .540 & 13.457 .994 & 14.635 .853 \\
\hline BBRI & 22.007 .466 & 23.933 .966 & 26.696 .102 & 29.710 .518 & 32.136 .306 \\
\hline BBTN & 1.587 .761 & 2.441 .913 & 2.819 .655 & 2.566 .874 & 18.609 \\
\hline BMRI & 19.842 .722 & 13.628 .888 & 19.929 .962 & 23.293 .576 & 26.221 .670 \\
\hline JSMR & 1.502 .884 & 2.209 .591 & 2.079 .901 & 1.945 .289 & 2.514 .738 \\
\hline PGAS & $\$ 516$ & $\$ 334$ & $\$ 51$ & $\$ 265$ & $\$(260)$ \\
\hline PTBA & 1.671 .606 & 1.690 .068 & 3.926 .107 & 3.959 .613 & 3.150 .656 \\
\hline PTPP & 762.336 & 1.050 .287 & 1.582 .903 & 2.338 .590 & 2.401 .906 \\
\hline SMGR & 4.204 .110 & 4.593 .658 & 2.192 .459 & 3.196 .582 & 3.974 .350 \\
\hline TLKM & 21.260 .713 & 27.079 .913 & 30.554 .668 & 25.932 .948 & 27.221 .345 \\
\hline WIKA & 663.116 & 1.047 .446 & 1.006 .198 & 2.431 .031 & 2.385 .883 \\
\hline
\end{tabular}

\section{Data Weighted Average Cost of Capital} (WACC)

Menurut data WACC, dapat dilihat bahwa saham ANTM yang terendah dengan nilai minus dan saham BBRI, BBTN, dan PTBA memiliki WACC diatas 0 .

Tabel 8. Data Weighted Average Cost of Capital (WACC)

\begin{tabular}{|l|c|c|c|c|c|}
\hline & 2015 & 2016 & 2017 & 2018 & 2019 \\
\hline ANTM & $(0,058)$ & 0,00488 & $(0,015)$ & 0,105 & 0,00082 \\
\hline BBNI & 0,166 & 0,165 & 0,201 & 0,166 & 0,17 \\
\hline BBRI & 0,283 & 0,224 & 0,223 & 0,222 & 0,232 \\
\hline BBTN & 0,204 & 0,234 & 0,203 & 0,186 & 0,011 \\
\hline BMRI & 0,262 & 0,174 & 0,178 & 0,174 & 0,177 \\
\hline JSMR & 0,086 & 0,09 & 0,06 & 0,062 & 0,065 \\
\hline PGAS & 0,088 & 0,068 & 0,029 & 0,007 & 0,0008 \\
\hline PTBA & 0,219 & 0,200 & 0,338 & 0,317 & 0,225 \\
\hline PTPP & 0,161 & 0,107 & 0,128 & 0,13 & 0,084 \\
\hline SMGR & 0,151 & 0,134 & 0,063 & 0,087 & 0,066 \\
\hline TLKM & 0,19 & 0,222 & 0,226 & 0,182 & 0,185 \\
\hline WIKA & 0,099 & 0,09 & 0,084 & 0,094 & 0,108 \\
\hline
\end{tabular}

Tabel 9. Data Invested Capital (IC)

\begin{tabular}{|c|c|c|c|c|c|}
\hline & 2015 & 2016 & 2017 & 2018 & 2019 \\
\hline ANTM & 18.504 & 18.718 & 17.872 & 20.385 & 22.113 \\
\hline BBNI & 105.809 & 126.854 & 146.301 & 163.089 & 182.737 \\
\hline BBRI & 158.835 & 206.230 & 226.772 & 254.616 & 275.868 \\
\hline BBTN & 34.080 & 39.050 & 50.135 & 59.984 & 66.085 \\
\hline BMRI & 155.655 & 198.279 & 222.554 & 251.945 & 290.975 \\
\hline JSMR & 18.446 & 18.908 & 40.875 & 39.365 & 37.272 \\
\hline PGAS & $\$ 5.485$ & $\$ 5.523$ & $\$ 5.514$ & $\$ 5.313$ & $\$ 4.934$ \\
\hline PTBA & 8.462 & 9.151 & 13.345 & 16.307 & 18.116 \\
\hline PTPP & 4.559 & 9.002 & 13.135 & 19.439 & 20.803 \\
\hline SMGR & 24.955 & 27.924 & 31.357 & 34.425 & 55.327 \\
\hline TLKM & 95.348 & 100.087 & 107.732 & 113.674 & 104.470 \\
\hline WIKA & $(1.593)$ & $(1.538)$ & $(6.268)$ & $(2.727)$ & $(1.412)$ \\
\hline
\end{tabular}

Sedangkan dilihat dari data invested capital, didapat bahwa saham BBRI dan BBTN memiliki invested capital terbesar selama tahun 2015 hingga 2019. Namun untuk saham WIKA memiliki invested capital dibawah 0 .

3. Menghitung EVA

Tabel 10. Hasil perhitungan metode EVA (Dalam miliaran rupiah)

\begin{tabular}{|l|c|c|c|c|c|}
\hline & 2015 & 2016 & 2017 & 2018 & 2019 \\
\hline ANTM & 265 & $(105)$ & $(516)$ & $(955)$ & $(1.494)$ \\
\hline BBNI & $(10.977)$ & $(10.431)$ & $(15.601)$ & $(13.777)$ & $(16.600)$ \\
\hline BBRI & $(22.989)$ & $(22.432)$ & $(24.031)$ & $(26.859)$ & $(31.911)$ \\
\hline BBTN & $(5.367)$ & $(6.706)$ & $(7.394)$ & $(8.638)$ & $(736)$ \\
\hline BMRI & $(21.053)$ & $(2.920)$ & $(19.767)$ & $(20.675)$ & $(25.315)$ \\
\hline JSMR & $(84)$ & 501 & $(381)$ & $(503)$ & 78 \\
\hline PGAS & $\$ 30$ & $\$(42)$ & $\$(113)$ & $\$(144)$ & $\$(304)$ \\
\hline PTBA & $(182)$ & $(146)$ & $(589)$ & $(1.221)$ & $(939)$ \\
\hline PTPP & 24 & 82 & $(106)$ & $(203)$ & 639 \\
\hline SMGR & 419 & 837 & 211 & 185 & 321 \\
\hline TLKM & 3.073 & 4.813 & 6.191 & 5.136 & 7.817 \\
\hline WIKA & 821 & 909 & 1.537 & 2.175 & 2.233 \\
\hline
\end{tabular}

Metode EVA merupakan metode untuk memvaluasi perusahaan berdasarkan laba operasional, WACC masing-masing perusahaan, serta Invested Capital. Metode EVA > 0 menunjukkan bahwa perusahaan 
memberikan keuntungan ekonomis kepada para pemengang saham. Jika EVA $=0$, menunjukkan bahwa hutang dan modal perusahaan berimbang dengan laba operasional. Sedangkan jika EVA $<0$, maka perusahaan tidak dapat memberikan keuntungan ekonomis tambahan kepada para pemegang saham.

Berdasarkan metode EVA, dapat dilihat bahwa sektor perbankan (BBNI, BBRI, BBTN, BMRI) menampilkan hasil economic valueadded yang negatif, dikarenakan invested capital (IC) yang lebih besar dibanding penerimaan operasional sebelum kena pajak (NOPAT).

Bisnis perbankan bergerak untuk penyaluran kredit dan pemberian bunga deposito. Hampir seluruh bisnis perbankan memberikan hasil EVA negatif dikarenakan perbankan yang overcapitalized dan penyaluran kredit yang belum efektif kepada debitur (Ahmadyan \& Khansari, 2018). NOPAT yang rendah disebabkan oleh pendapatan bunga yang belum maksimal dan biaya operasional perbankan yang besar, menyebabkan hasil EVA negatif untuk sektor perbankan, terutama dalam penelitian ini yaitu perbankan BUMN (Susanti, Dimyati, \& K. Sari, 2020).

Untuk sektor selain perbankan, EVA negatif disebabkan oleh operasional yang belum maksimal serta pengelolaan dana jangka panjang yang dimiliki oleh perusahaan untuk investasi. Invested capital yang ada digunakan untuk investasi perusahaan, menyebabkan penilaian economic value added menjadi negatif untuk sementara, dan berpotensi untuk digantikan menjadi lebih baik di masa depan, seperti sektor pertambangan (ANTM, PTBA) yang masih memberikan hasil EVA negatif. Namun ada perbaikan untuk PTBA terlihat dari 2018 ke 2019 dengan hasil negatif yang mulai mengecil sedangkan ANTM yang membesar diakibatkan oleh NOPAT yang masih kecil berbanding dengan invested capital yang membesar setiap tahun. Selain itu, harga komoditas dan permintaan juga berpengaruh terhadap laba ANTM dan PTBA (Sajekti \& Syamawati, 2017). Sektor konstruksi juga dipengaruhi oleh model bisnis untuk memiliki capital sebelum membangun infrastruktur. EVA
PTPP memberikan hasil yang besar di tahun 2019 dikarenakan WACC yang paling kecil diantara 5 tahun berjalan, sehingga EVA tahun 2019 sebesar Rp 639 miliar. Namun WIKA dapat mengelola invested capital nya dengan pengurangan IC di tahun 2018 dan 2019 yang menyebabkan EVA ada di Rp 2,1 triliun dan 2,2 triliun dengan projek yang tetap berjalan setiap tahunnya.

Secara garis besar, perhitungan menggunakan Valuasi Dividend Discounted Model (DDM) dan Economic Value Added (EVA) digunakan untuk mengambil keputusan pembelian saham perusahaan, dalam hal ini BUMN yang listing di Bursa Efek Indonesia. Perbankan memberikan hasil minus pada metode EVA, dikarenakan komponen Invested Capital (IC) yang besar sehingga memberikan hasil EVA yang besar. Dalam hal ini, EVA negatif pada bisnis perbankan menunjukkan overcapitalized dan pemanfaatan penyaluran kredit yang belum maksimal dari tahun ke tahun akibat biaya operasional yang besar serta short-term debt yang besar diakibatkan pencatatan uang nasabah di perbankan. EVA negatif pada bisnis diluar perbankan menunjukkan NOPAT yang didapatkan lebih kecil dibandingkan invested capital perusahaan. Untuk metode DDM, terdapat kekurangan, yaitu data yang dipakai adalah data dari 2015 hingga 2019 untuk memprediksi tahun 2020. Metode DDM memiliki kekurangan dari sisi fleksibilitas makro ekonomi, dikarenakan 2020 yang berefek akibat wabah pandemik. Namun, pola pembagian dividen dapat dijadikan acuan untuk memvaluasi perusahaan.

\section{KESIMPULAN}

Berdasarkan analisis saham menggunakan metode DDM dan EVA, terdapat tujuh (7) saham yang layak diinvestasikan, antara lain BBNI, BBRI, BMRI, PTBA, SMGR, TLKM, dan WIKA. Saham BBNI, BBRI, BMRI, dan PTBA merupakan saham yang undervalue menurut metode dividend discounted model. Sedangkan SMGR, TLKM, dan WIKA merupakan saham yang memberikan keuntungan ekonomis tambahan kepada para pemegang saham. Penggunaan metode DDM dan EVA memberikan perspektif lain mengenai valuasi saham, selain dari metode PER dan PBV. Walaupun menggunakan data tahunan, 
investor tetap dapat menggunakan valuasi tersebut untuk berinvestasi saham dan memiliki gambaran terhadap saham yang cocok disimpan untuk jangka panjang. Selain itu, di masa CoVID-19, valuasi menggunakan DDM dan EVA dapat dihitung kembali dengan mempertimbangkan laporan kuartalan BUMN.

Bagi Investor yang ingin membeli saham, sebaiknya melakukan analisis terhadap saham yang ingin dibeli dengan berbagai metode yang diyakini. Metode DDM dan EVA memberikan perspektif untuk investor pakai agar mengetahui saham mana saja yang dapat memberikan keuntungan melalui dividen dan nilai ekonomis tambahan yang akan diterima. Metode valuasi yang akan dipakai juga seharusnya mempertimbangkan aspek pandemik CoVID-19 yang terjadi di Indonesia, agar tidak terlalu berekspektasi dengan imbal hasil tinggi dari pasar modal.

Bagi dewan direksi perusahaan sebaiknya melakukan corporate governance yang lebih baik lagi di perusahaan masing-masing agar setiap tahun perusahaan dapat membagikan dividen dan bisa berpotensi memberikan keuntungan tambahan kepada para pemegang saham. Para pemegang saham memiliki harapan yang besar kepada perusahaan, sehingga jangan mengecewakan pemegang saham tersebut.

Penelitian selanjutnya dapat memperluas data penelitian, seperti menggunakan Indeks LQ45 ataupun Kompas100 agar data lebih banyak dan lebih mudah digunakan serta penggunaan metode valuasi lainnya, seperti Benjamin Graham Model, EV/EBITDA, dan lainnya.

\section{DAFTAR PUSTAKA}

Ahmadyan, A., \& Khansari, R. (2018). Application of Economic Value Added in the Banking Sector of Iran. Journal of Money and Economy, 291-318.

Arta, I. A. (2017). Status Kepemilikan Badan Usaha Milik Negara (BUMN) Persero Setelah Dikuasai Oleh Pihak Swastas. Jurnal IUS, 178-188.

Ashari, B. H., Wibawa, B. M., \& Persada, S. F. (2017). Analisis Deskriptif dan Tabulasi Silang Pada Konsumen Online Shop di Instagram (Studi Kasus 6 di Kota
Surabaya). Jurnal Sains dan Seni, 17-21.

Bakhri, S. (2018). Minat Mahasiswa Dalam Investasi di Pasar Modal. Fakultas Syariah dan Ekonomi Islam, 10, 146-157. doi:10.24235/amwal.v10i1.2846

Berenson, M. L., Levine, D. M., \& Krehbiel, T. C. (2015). Basic Business Statistics. New Jersey: Pearson.

Costin, D. M. (2017). Economic Value Added - A General Review of the Concept. Economic Sciences Series, 168-173.

Damodaran, A. (1995). Investment Valuation: Tools and Techniques for Determining the Value of Any Asset. United States: John Wiley \& Sons.

Dewan Standar Akuntansi Keuangan. (2013). PSAK. Jakarta: Dewan Standar Akuntansi Keuangan.

Echterling, F., \& Eierle, B. (2015). Mean Reversion Adjusted Betas Used In Business Valuation Practice : A Research Note. J Bus Econ, 759-792.

Fauziah, M. (2014). Analisis Risiko Pada Portofolio Saham Syari'ah Menggunakan Value at Risk (VaR) Dengan Pendekatan Generalized Pareto Distribution (GPD). Jurnal Konvergensi, 85-104.

Filbert, R. (2017). Investasi Saham Ala Fundamentalis Dunia. Jakarta: PT. Elex Media Komputindo.

Ginting, N. (2017). Privatisasi Badan Usaha Milik Negara (BUMN) Kepemilikan Saham Sebagai Upaya Meningkatkan Kesejahteraan Umum. Neilman Ginting, 115.

Gitman, L. J., \& Zutter, C. J. (2015). Principal of Managerial Finance. United States of America: Pearson.

Graham, B. (1973). The Intelligent Investor. New York: Perfect Bound. Diambil kembali dari

http://webcontent.harpercollins.com/text/e xcerpts/pdf/0060583282.pdf

Hartono, J. (2016). Teori Portofolio dan Analisis Investasi. Yogyakarta: BPFE.

Hartono, J. (2017). Teori Portofolio dan Analisis Investasi. Yogyakarta: BPFE-Yogyakarta.

Herlianto, D. (2013). Manajemen Investasi Jurus 
Mendeteksi investasi Bodong. Yogyakarta: Gosyen Publishing.

Isidore, R. R., \& Christie, P. (2018). Fundamental Analysis Versus Technical Analysis : A Comparative Review. International Journal of Recent Scientific Research, 9, 23009-23013.

doi:http://dx.doi.org/10.24327/ijrsr.2018.0 901.1380

Ivanovski, Z., Ivanovska, N., \& Narasanov, Z. (2015). Application of Dividend Discounted Valuation at Macedonian Stock-Exchange. UTMS Journal of Economics, 147-154.

Kesuma, Y. F. (2014). Analisis Laporan Keuangan Sebagai Dasar Dalam Penilaian Kinerja Keuangan PT. Budi Satria Wahana Motor. Jurnal Akuntansi dan Keuangan, 93-121.

Khan, M. T., Tan, S. H., \& Chong, L. L. (2017). Perception of Past Portfolio Returns, Optimism, and Financial Decisions. Review of Behavioral Finance, 9, 79-98. doi:10.1108/RBF-02-2016-0005

Kieso, D. E., Kimmel, P. D., \& Weygandt, J. J. (2015). Financial Accounting 3rd Edition. Wiley.

Kieso, D. E., Weygandt, J. J., \& Warfield, T. D. (2014). Intermediate Accounting. Wiley.

Loeb , S., Dynarski, S., McFarland, D., Morris, P., Reardon, S., \& Reber, S. (2017). Descriptive Analysis in Education : A Guide For Researchers. Institute of Education Sciences, 1-53.

Maith, H. A. (2013). Analisis Laporan Keuangan Dalam Mengukur Kinerja Keuangan Pada PT. Hanjaya Mandala Sampoerna Tbk. Jurnal EMBA, 619-628.

Mulyadi, M. (2011). Penelitian Kuantitatif dan Kualitatif Serta Pemikiran Dasar Menggabungkannya. Jurnal Studi Komunikasi dan Media, 127-138.

Nasution, Y. S. (2015). Peranan Pasar Modal Dalam Perekonomian Negara. HUMAN FALAH, 95-112.

Olsen, R. A. (2014). Financial Risk Perceptions : A Consciousness Perspective. Qualitative Research in Financial Markets, 6, 66-74. doi:10.1108/QRFM-07-2012-0023
Olweny, T. (2011). The Reliability of Dividend Discount Model in Valuation of Common Stock at the Narubian Stock Exchange. International Journal of Business and Social Science, 127-141.

Ong, E. (2016). Technical Analysis For Mega Profit. Jakarta: PT. Gramedia Pustaka Utama.

Otoritas Jasa Keuangan. (2019). Sikapi Uangmu. Diambil kembali dari OJK: https://sikapiuangmu.ojk.go.id/FrontEnd/ CMS/Category/63

Pardiansyah, E. (2017). Investasi Dalam Perspektif Ekonomi Islam : Pendekatan Teoritis dan Empiris. Economica : Jurnal Ekonomi Islam, $\quad 8, \quad 337-373$. doi:http://dx.doi.org/10.21580/economica. 2017.8.2.1920

pefindo.com. (2019). Pefindo. Diambil kembali dari Pefindo: https://pefindo.com/index.php/pageman/p age/beta-saham.html

Pring, M. J. (2014). Technical Analysis Explained. New York: Mc Graw Hill.

Purbawati , N. L., \& Dana, I. (2016). Perbandingan Volatilitas Indeks Harga Saham Gabungan Sebelum dan Setelah Krisis Subprime Mortgage. E-Journal Manajemen Unud, 1014-1042.

Rahadjeng, E. R. (2011). Analisis Perilaku Investor Perspektif Gender Dalam Pengambilan Keputusan Investasi di Pasar Modal. Jurnal Humanity, 90-97.

Raneo, A. P., \& Muthia, F. (2018). Penerapan Model GARCH Dalam Peramalan Volatilitas di Bursa Efek Indonesia. Jurnal Manajemen dan Bisnis Sriwijaya, 194202.

Reuters. (2019, May 31). Reuters. Diambil kembali dari Reuters: https://www.reuters.com/article/usindonesia-ratings-s-p/sp-raisesindonesias-rating-to-bbb-on-strongeconomic-prospects-idUSKCN1T10VF

Sabrol, A., \& Sverer, F. (2016). A Review of The Economic Value Added Literature and Application. UTMS Journal of Economics, 19-27. 
Sajekti, T., \& Syamawati, E. M. (2017). Analisis Harga Komoditas dan Harga Pokok Penjualan Serta Pengaruhnya Terhadap Laba Kotor Pada PT. ANEKA TAMBANG (PERSERO), TBK. Jurnal Indonesia Membangun, 1-15.

Salim, J. (2010). 108 Tanya Jawab Tentang Investasi. Jakarta: Visi Media Pustaka. Diambil kembali dari https://books.google.co.id/books?hl=en\&l $\mathrm{r}=\& \mathrm{id}=\mathrm{RUhYT}$ 9sId1 IC\&oi=fnd \&pg=PA $115 \& \mathrm{dq}=\mathrm{apa}+\mathrm{itu}+\mathrm{investasi \& ots}=4 \mathrm{~L}-$ V_IDGsq\&sig=h_EizT34oU8YeZuhBi5 $\mathrm{mJVmzy} 2 \mathrm{Q} \&$ redir_esc $=\mathrm{y} \# \mathrm{v}=$ onepage $\& \mathrm{q}$ $=$ investasi $\& \mathrm{f}=$ false

Sekaran, U., \& Bougie, R. (2016). Research Methods for Business, A Skill-Building Approach. Chichester, West Sussex: Wiley.

Seputro, H. Y., Pratama, R. S., \& Klaudia, S. (2017). Pengaruh Pemahaman Investasi, Modal Minimal Investasi dan Motivasi Terhadap Minat Mahasiswa Berinvestasi di Pasar Modal. Jurnal Penelitian Teori dan Terapan Akuntansi, 23-35.

Setiawan, R. A. (2015). Peranan Pasar Modal Dalam Perekonomian Ummat Islam. $A L$ INTAJ, 37-51.

Sharma, A. K. (2010). Economic Value Added Literature Review. International Journal of Economics and Finance, 200-220.

Sidik, S. (2020, November 17). RI Susah Maju karena Literasi Keuangan Rendah, Cuma 37\% Gaes! Diambil kembali dari CNBC Indonesia:

https://www.cnbcindonesia.com/market/2 0201117132955-17-202428/ri-susahmaju-karena-literasi-keuangan-rendahcuma-37-gaes

Srivastava, N. (2015, May 11). Does Governance Structure Have Any Effect on Firm Performance During The Financial Crisis. Journal of Strategy and Management, 8, 368-383. doi:10.1108/JSMA-02-20150014

Subramanyam, K. R., \& Wild , J. J. (2017). Financial Statement Analysis. McGrawHill.
Sugiyono. (2013). Metode Penelitian Kuantitatif, Kualitatif, dan R\&D. Bandung: Penerbit Alfabeta Bandung.

Sugiyono. (2019). Statistika Untuk Penelitian. Bandung: Penerbit Alfabeta Bandung.

Sugiyono, P. (2018). Metode Penelitian Kuantitatif, Kualitatif, dan $R \& D$. Yogyakarta: Alfabeta.

Susanti, I., Dimyati, M., \& K. Sari, N. (2020). Analisis Economic Value Added (EVA) dan Market Value Added (MVA) Sebagai Alat Ukur Kinerja Keuangan Bank Umum Swasta Nasional (BUSN) Devisa Go Public Tahun 2014-2018. JIMAT (Jurnal Ilmiah Mahasiswa Akuntansi), 520-526.

Tandelilin, E. (2010). Portofolio dan Investasi, Teori dan Aplikasi. Yogyakarta: Kanisius. Tandelilin, E. (2017). Portofolio dan Investasi. Yogyakarta: Kanisius. Diambil kembali dari

https://books.google.co.id/books?id=YLO RI8ul44kC\&printsec $=$ frontcover\&hl=id\# $\mathrm{v}=$ onepage $\& \mathrm{q} \& \mathrm{f}=$ false

Undang - Undang Pasar Modal. (1995). Jakarta: Republik Indonesia.

Undang Undang Badan Usaha Milik Negara. (2003). Undang Undang Republik Indonesia Nomor 19 Tahun 2003. Badan Usaha Milik Negara, 35.

Wicaksono, A. (2020, December 3). Tingkat Literasi dan Inklusi Keuangan Meningkat. Diambil kembali dari CNN Indonesia: https://www.cnnindonesia.com/ekonomi/ 20201203123254-78-577515/tingkatliterasi-dan-inklusi-keuangan-meningkat

Wright, R. H., \& Sim, T. (2018). Stock Valuation Using The Dividend Discount Model : An Internal Rate of Return Approach. Growing Presence of Real Options in Global Financial Markets, 19-32.

Yulianti, N., \& Silvy, M. (2013). Sikap Pengelola Keuangan dan Perilaku Perencanaan Investasi Keluarga di Surabaya. Journal of Business and Banking, 57-68.

Zahera, S. A., \& Bansal, R. (2018). Do Investors Exhibit Behavioral Biases in Investment Decision Making? A Systematic Review. Qualitative Research in Financial 
p-ISSN: 0216-1249

e-ISSN: 2541-4100
Jurnal Administrasi Bisnis [JAB]

Vol 17 No 2 Desember 2021

Markets, $\quad 10, \quad 210-251$.

doi:10.1108/QRFM-04-2017-0028 